\title{
LA CONSTRUCCION DEL DICTADOR POPULISTA EN EL PUEBLO SOY YO
}

POR

\author{
LUIS MARTUL TOBIO \\ Universidad de Santiago de Compostela
}

La novela de la dictadura o del poder personal quiere articular literatura (arte) y política, considerados frecuentemente como opuestos, y que hoy sabemos tan próximos como procedimientos de verdad, aunque tan difícilmente elaborables ${ }^{1}$. En este intento de articulación, y en el caso de este tipo de novela, tan decisiva resulta la concepción que se pueda tener de la política como de la estética. Inevitablemente el producto literario no será el mismo. Es sabido cómo en Miguel A. Asturias una densa convicción de lo unificado del fenómeno dictatorial le condujo a construir una interpretación del Estado (y de la política) en la que la actividad de las fuerzas antagónicas está borrada, o mejor, las claves de una cierta situación se hipostasian, con el objeto de crear una solución totalizante ${ }^{2}$.

Es también evidente que las narraciones de realismo social y de denuncia se basan en una noción concreta de política. El escritor emplea el material de categorías fácilmente expandibles en el terreno literario: clases sociales, instituciones, estructuras de organización, aparatos de Estado, además de espacios de trabajo. Todo este entramado sustenta la idea de una política como expresión de lo económico-social. Reducida en su autonomía, negada su capacidad de invención, la política viene a ser una práctica calculable y medible ${ }^{3}$. Y por aquí podemos llegar al por qué del fracaso de la novela de compromiso político o de denuncia.

No obstante, la novela de dictadura contiene por sus planteamientos riesgos muy concretos. Fue objetivo muy apreciado en distintas disciplinas querer encontrar en el estudio y análisis de los entresijos del poder, las claves

\footnotetext{
${ }^{1}$ A. Badiou ha planteado nuevas interpretaciones de la política y la literatura. Alain Badiou, Manifeste pour la Philosophie. Paris: Seuil, 1989, 41-58.

${ }^{2}$ Este aspecto es comentado por Gerald Martin, "El Señor Presidente and How to Read it", Bulletin of Hispanic Studies, XLVII, 1970, 223-43. Tambien por E. Rodriguez Monegal, "Los dos Asturias", Revista Iberoamericana, XXXV, 67, 1969, 13-20.

${ }^{3}$ Véase Sylvain Lazarus, Peut-on penser la politique en interiorite? Paris: Les Conférences du Perroquet, 1985.
} 
que permitiesen la transformación de la sociedad. De ahi, los innumerables trabajos sobre el Estado capitalista de décadas pasadas. Esta postura fue compartida por más de uno de los escritores que se propusieron novelar una formación tan típica de América Latina como es la dictadura. Muchos de estos intentos, que enlazan con la corriente de realismo social, concluyeron en una visión muy crítica pero sociologista. En realidad, centrarse en el dictador implica ya una unilateralidad de partida, un olvido del postulado de que el secreto de la dominación está en los dominados y no en ella misma. Por eso, en los casos en que se formula un principio contradictorio, la flojedad y lo esquemático son sus notas definitorias. Adelantemos ya que éste es el caso de los personajes que protagonizan la revolución en la obra de Pedro J. Vera.

En $E l$ pueblo soy yo ${ }^{4}$, título que recoge, mutándola, la frase del rey francés $-y$ que viene a indicar, en un racimo de significados, el sesgo populista pero también el rasgo de la dualidad-bajo el "pueblo" se esconde el Estado - y el de la referencia europea como identificación o el concepto de encarnación como forma máxima de representación política- proyecta describir los mecanismos del poder personal, con su inherente denuncia, al tiempo que realizar una destrucción de la simbología unificadora y atemorizadora, hasta fragmentar su identidad por vía de la parodia y la ridiculización.

Pedro J. Vera es un escritor formado en el período en el que el relato criollista y realista social eran dominantes en Latinoamérica. Su obra se encauza por esa línea de relato comprometido. De hecho, en el libro de cuentos Los mandamientos de la ley de Dios (1972) tenemos el titulado “Viva Velasco! y otros alaridos" que trata la figura de un dictador. Presenta en su constitución muchos de los elementos que han de aparecer en la novela. Así, aspecto físico huesudo y grandilocuencia, parodia de esta expresión, su pasión por las obras públicas, leitmotiv: volverá, la denominación de "el Gran Ausente", y el desgobierno que deja en la comunidad. Este cuento sirve también para ayudar a comprobar que el modelo de dictador de El pueblo soy yo es Velasco Ibarra. Todavía hay otro cuento que anticipa algún otro material, más limitadamente. Es "Un ciudadano de París" en que se puede encontrar algún antecedente de la parte que transcurre en esa capital en la novela.

La narración estáenmarcada por hechos históricos que incluyen la referencia a la fundación y formación del país desde una franca actitud desmitificadora. El período efectivo que engloba la acción va desde algún instante entre las guerras mundiales (Velasco Ibarra es elegido presidente por primera vez en 1934) hasta comienzos de los sesenta (se menciona la revolución cubana). De manera global periodiza haciendo referencias a hechos como la segunda Guerra Mundial. Por lo demás, es evidente que el país es el Ecuador por la mención a los tres territorios propios de un país andino $o$ a acontecimientos como el desastre de la

${ }^{4}$ Las citas provienen de Pedro Jorge Vera, El pueblo soy yo. 2.ed., Barcelona: Seix Barral, 1976. 
guerra fronteriza con Perú (1941-42). Pero, sobre todo, el presidente caudillo o el dictador presidencial es sin duda Velasco Ibarra con el que coincide en infinidad de detalles: sus años de estudiante en la Sorbona, profesor a la vuelta, ascensión política hasta ser presidente de la Cámara de Diputados, sus derrocamientos y vueltas al poder desde el exilio, su autoproclamación de dictador y su expulsión en seis horas, su desagrado a la constitución avanzada de 1945 y su suspensión por decreto, su incapacidad política y conflictos constantes con estudiantes y militares, la organización de seguidores que preparaban sus retornos, el grupo de choque Arne, sus demostraciones de energía viajando a los lugares más remotos, su indefinición ideológica, incluso sus discursos vehementes, su dedo acusador extendido, su convicción de estar junto a las masas, es decir, su caudillismo populista, sus nominaciones "el Gran Ausente", el "Hombre Providencial", incluso en su carácter y físico es la reproducción de Velasco Ibarra, delgado y ascético.

En esta ocasión nos proponemos aislar solamente los componentes o semas fundamentales que constituyen al dictador.

La concepción del autor parte de una base sociológica. En primer lugar establece las causas sociales y psicológicas de su personaje para lo cual introduce el excurso biográfico de las primeras páginas que proporciona el modelo de presupuestos de expresividad social. El siguiente paso en la construcción es laarticulación de ciertos mecanismos que obedecen al imaginario del protagonista, que se vinculan a una función unificadora y que también se representa fantasmáticamente en Gabriel. El principio imaginario estará presente en todo impulso de unificación o de agrupación, por tanto afectando radicalmente a la conducta del dictador, pero muy claramente en ciertos aspectos: Las identificaciones históricas y de imagen, el presidente como encarnación del pueblo, y Gabriel como atribución a esta representación de la autoridad ancestral y constante. El último estadio es el conjunto de categorías de la dualidad que promueven ciertas secuencias, de clara herencia literaria, que se repiten en la narración, como son los monólogos interiores directos que ocurren en la terraza, escenario emblemático, y en el lecho. Categorías como la sexualidad, doblez/integridad, racionalismoe irracionalismo, progreso/atraso, teatralidad, pelelismo, que confluyen en un signofinal de poder comodisgregación e inconsistencia. En el plano del registro de la expresión del narrador esta fundamental concepción de la dualidad explica la utilización dominante - con instantes de condena directa- de ironía, sarcasmo y parodia ${ }^{5}$.

\section{LOS REFERENTES IDENTIFICADORES.}

En la descripción de la trayectoria del protagonista se aporta, de acuerdo con la concepción social, la extracción de clase, la psicología e ideología que lo

\footnotetext{
- Entre otros muchos, la ironía y el humor en las novelas de dictadura han sido comentados por Giuseppe Bellini, Il Mondo Allucinante. Milano: Cisalpino-Goliardica, 1976.
} 
mueve, y las instancias y procedimientos consagrados de ascensión social, según una lógica causal muy apretada. De todo esto sólo mencionaremos el planteamiento explicativo basado en el origen humilde y por el que tanto sufre humillaciones, especialmente las de la vida militar, como posee un agudo sentimiento de clase inferior. Su objetivo es realizar una ascensión social que significaría la satisfacción de su complejo psicológico cuando fuera presidente. "(...) la vindicación (...) su elevación y la victoria sobre la odiada casta castrense". Estos resortes promueven una actuación de esa personalidad cuya meta es invertir el signo inicial, pasar de obedecer a mandar. Su necesidad de vindicación sobre la sociedad implica la amplitud de sus pretensiones así como explica la constante manía persecutoria de sus siempre-activos enemigos. El es "un intelectual anhelante de instalarse en la historia". De aquí la transferencia es inmediata. Uno de los leitmotive es el del dictador como encarnación de la patria. Desde esta profunda pulsión personal, el imaginario impondrá en él un escenario de proyección a un mundo trascendental. La intensidad de sus complejos se traslada a sus mitomanías y a su papel en la sociedad y en la historia. De este modo surge una personalidad dual que oscila entre la realidad y su imaginario. Su conducta vacilante está guiada por su odio/temor a los militares y su angustia a ser depuesto, y por la convicción en su función salvífica de la patria. El será el individuo providencial de quien depende la posibilidad de que la nación misma se realice. Se considera predestinado y como tal su tarea es una acción mística.

En las numerosas definiciones de su relación armónica con el país -para lo cual elabora toda una teoría política: el "plan del general contentamiento"llega a considerarse en términos religiosos. Es un consagrado que se entrega a un culto del que él es el gran oficiante. En este rito hay una cierta escenografía, "silencio profundo", siente el "llamado" y entra en trance "se magnetizaba", para llegar a la fusión con la patria "y se instalaba en el corazón mismo de su tierra." Se identifica con Cristo "ungido como el único", lo que se corrobora en la opinión de un oponente "frente al ídolo de carne y hueso a quien venerar como la personificación del Cristo sacratísimo". En sus ensoñaciones discurren sus deseos reprimidos, su megalomanía, debilidades narcisistas. En esta lógica, si primero es el pueblo quien lo legitima, según evolucione, será Dios quien lo ha escogido para esa tarea. "El pueblo lo había votado (...) mas era Dios quien le entregaba el país."

El dictador en esta narración está construido teniendo en cuenta la serie histórica, cultural y literaria. Adquiere determinados significados por su adscripción a una simbología que el narrador emplea intencionalmente.

Además de aparecer como representante de lo europeo, recoge la herencia del intelectual del siglo XIX, del que viene a ser su parodia, el cual vislumbraba un horizonte continental y participaba de un discurso civilizador y fundacional. Detrás de sus palabras se translucen las imágenes de los próceres de los que él se considera su heredero. Por eso recibe el título de "El Hombre de América" o 
"El Mirabeau de los Andes", pensador, teórico y constructor, que vive en el exilio y desde el cual escribe cartas a la patria, condenando el orden vigente. La imagen de Montalvoes evidente, más patente cuando Tejada repite prácticamente la frase de aquél a la muerte de García Moreno (pero no ol videmos que también se identifica con éste en otros momentos de la acción).

El relato está recorrido por sucesivos apodos en relación directa con su significación política y cultural. Son las denominaciones arquetípicas: El Mesías, el Profeta, el Gran Ausente, el Constructor, el Salvador de la Patria, el Hombre del Petróleo. Atribuciones mechadas de frases ("Decidido a quemar las naves", "Adiós a las armas para siempre", "Señor no hay que ganar tanto") y gestos, con intención paródica, que remiten a otros textos y personalidades históricas o bien hacen recordar los personajes de Asturias o de Carpentier.

\section{CATEGORIAS DE LA DISGREGACION. FACTOR SEXUAL.}

Se relaciona directamente con la cuestión del poder. En la estela de una concepción psicológica muy divulgada, se relaciona su inclinación al poder con condición inhibida o acomplejada y que, en general, su conducta está determinada por los complejos, por su impotencia sexual, en primer lugar ${ }^{6}$. Esto explica la generación, por un lado, de actos de índole compensatoria, de la sublimación que se patentiza en un conjunto de auto-estimaciones y justificaciones, $y$, por el otro, el autoritarismo y la represión, siempre que su inseguridad profunda aflora. Entre estos dos polos transcurre la conducta vacilante, siempre a merced de la decisión espontánea y caprichosa o de la inhibida.

La inseguridad como rasgo profundo es el secreto de su autoridad. En consecuencia, su conducta viene definida por la falsedad. La desconexión entre apariencia y verdad, hecho axial en la narración, genera la dualidad como característica constitutiva que permea a los grupos sociales de poder y del gobierno.

En el comportamiento del dictador, en su apariencia misma, se aprecia la manifestación delatora y la ocultación de su realidad última. Los hábitos austeros, la frugalidad, la seriedad. Su fisonomía angulosa y figura magra expresan el constreñimiento de un posible desbordamiento orgánico y vital y apuntan a la condición reprimida: "Abstemio por temperamento y por principios el doctor accedió a beber una copita." y "Flaco, alto, nervudo, parco en el yantar, abstemio absoluto, le bastaban pequeñas raciones y unas pocas horas bien dormidas, para reponer las energías gastadas."

Por tanto, como lo que quiere el autor es desmitificar al déspota, desde el comienzo mismo de la narración suministra la información precisa para que, así desmontado, pueda ofrecerlo en detalle, de acuerdo a un proceso constante de

\footnotetext{
${ }^{6}$ Un estudio sobre aspectos psicol6gicos del dictador referidos al creado por Carpentier se halla en Georges Puisset, "Approche sociopsychanalytique du El recurso del método de Alejo Carpentier", Imprévue, Numéro Spécial, 1974, 57-108.
} 
destrucción por la ridiculización $\mathrm{n}^{7}$. La secuenciainicial proporciona datos decisivos de la personalidad mediante a) un procedimiento que permite la actualización de la estructura de la dualidad apariencia/realidad profunda: la conversación con los amigos Villagómez y Ribadeneira, y b) la vinculación poder político y sexualidad: la rememoración de González Tejada. Ambos son complementarios pues el primero contiene el que será un leitmotiv: "Siempre supiste mandar", el cual al poner en marcha los recuerdos del dictador, permitirá conocer su condición verdadera.

En la primera de estas instancias los dos amigos atribuyen a una supuesta personalidad compacta y coherente su disposición natural a mandar. Más aún, inconscientemente definen su capacidad de mando por la prohibición la cual se bifurca en dos significados: a) Una aparente inclinación innata a dirigir, por el gusto mismo de ejercitar el poder. De ahr que interpreten el hecho de que les prohibió continuar la aventura con las servicias pero no para aprovecharse él exclusivamente sino para mandar por mandar. Se toca así este aspecto muy tratado del poder por sucesivas autores. La mención a "desde chico" lleva a esta posibilidad de una tendencia inicial; b) Para obtener el segundo significado hay que esperar a la rememoración de González Tejada. En sus recuerdos se destruye la imagen de poder por primera vez, y se subvierte el significado de la frase. Esa prohibición es la que ejercía, y ejerce, el protagonista sobre sí mismo. $\mathrm{El}$ ansia de poder se revela como un acto desesperado por ocultar su falta, su impotencia. Esta deficiencia sexual va a actuar irónicamente al significar carencia de fuerza en alguien que detenta el poder y que se rodea de sus atributos. Incluso, la figura del dictador como epítome de la autoridad, de la norma y de la ley (personal), y, en este caso, de la lengua, en su incontinencia verbal, y de la imagen paternal, parece implícitamente referible al símbolo fálico. La relación cómica con su debilitado órgano fálico resulta inevitable.

Los recuerdos han estado reprimidos, borrados de la conciencia, y ahora afloran permitien do comprender la motivación de su conducta política. Represión sexual, que es una de las fuentes de comicidad más continuadas. Los complejos sexuales son los generadores de situaciones que significan al dictador, destituyéndolo. Además, hay que tener presente el contexto latente de la mentalidad machista que adquirirá más relevancia una vez que él revele una tendencia homosexual. En realidad, el efecto de compensación y desviación está en el origen de su auto-imagen de gran intelectual y de conductor de pueblos. La idea de sacrificio sexual se desplaza a su sacrificio por la patria. Articulado a este significado fundamental de la sexualidad en el protagonista, el narrador va a dedicarse a destruir la tradicional figura de temor, como ya apuntamos, al someterlo a una serie de episodios que provocan su disolución.

${ }^{7}$ R. Gonzalez Echevarria, The Voice of the Masters. Austin: University of Texas Press, 1985. Este autor comenta, desde una perspectiva diferente a la de Vera, la destrucción del mito de la autoridad en la novela de dictadura. 
El primero de estos episodios tiene una franca intención paródica. Es el encuentro con Ana Isabel. En la cima de su carrera política el presidente populista encuentra la mujer soñada. La posibilidad de unificar la realización social y afectiva parece real. En un primerinstante el mecanismo de sublimación en lo espiritual es el que actúa: la relación con la mujer se debería a la subyugación intelectual por él "porque ella no era una beldad cualquiera sino una mujer superior prendada de su inteligenciay su sabiduría y su al to destino". En un segundo instante se pone de relieve la distancia entre su egolatría y su débil constitución como hombre común.

Sobre la ecuación irónica de dictador igual a poder impotente, es decir, de un poder falso, el narrador desenvuelve nuevos lances degradativos. La situación inicial parte de la deficiencia. Pero un dictador impotente es inconcebible. De ahí que la mejoría a obtener cristalice en un proceso cuyo resultado es su obtención. Ahora bien, toda la secuencia cuenta con unidades en las que el protagonista es sistemáticamente rebajado. La escena inicial en el dormitorio y las prácticas de hechicería y la oración se suman para ofrecer la imagen cómica de una figura tan poderosa.

Pero esta secuencia aporta nuevos significados. Este personaje acostumbra a protegerse en la escapatoria espiritualista o en la propiciatoria. Esta reacción última manifiesta un modelo psicológico que, por encima de sus autocomplacencias, es dependiente de ayudas externas, no sólo confía en soluciones milagrosas o en la intervención de personajes no ya celestiales, que cabrían en la epopeya, sino en otros más terrenales y faltos de aureola como la hechicera. Encontramos algo que vuelve a erosionar el símbolo de autoridad: aquél que parece omnipotente es tan débil como para depender de prácticas propiciatorias que escapan a su control y de creencias sincréticas que llevan a dudar de su racionalidad.

La impotencia sexual inicial, y recurrente, en su conexión con una pulsión por el poder, respondía más a la debilidad, a la necesidad de ocultar algo y, por tanto, explica la represión política como el instante en que, teniendo que actuar, teme reconocer públicamente que no puede o que no sabe. No es la expresión de una fuerza maléfica que se podría haber simbolizado en lo satánico o en otra fórmula suministrada por el stock mítico. Esto sería comunicarle, a pesar de todo, una grandeza, un cierto significado heroico, aunque negativo. Por el contrario, este presidente caudillista está concebido como una figura de lo normal, de lo común, carente de un poder o cualidades especiales. Lo sexual remitido al poder está para desmitificar, destituir y ridiculizar, para mostrar su consistencia endeble e insegura, y esto es lo que propone la narración: cómo lo falto de cualidades o atributos, lo más débil, puede convertirse en el detentador de la violencia y del poder. Por tanto, lo curioso está, no tanto en aquellos que tuvieron una fuerza para desencadenarla, sino en la paradoja del ser que adquiere un poder que no le corresponde, dada su debilidad ${ }^{8}$. González Tejada

${ }^{8}$ Sobre "el lado humano", véase Mario Benedetti, El recurso del supremo patriarca (México: Nueva Visión, 1975), 16-17. 
es el dictador ridículo pero no por eso menos significativo. Cuando él recuerde, ya en la segunda parte, su relación amorosa con Ana Isabel, se referirá a ese período como "Un pasado vibrante, casi épico". Lo épico, así pues, es un hecho mínimo para criterios objetivos, pero grandioso para este personaje.

A lo largo de la narración se suceden todavia una serie de secuencias agrupadas en torno a un doble protagonismo que tiene lo sexual como eje. Son las relaciones con Luz María y con Marjorie. Las constantes y planteamientos se mantienen, sólo que se produce una evolución degradativa. Con el paso de los años el dictador se entrega más a su vocación oficial y renuncia a la satisfacción sexual plena, sustituida por prácticas deformadas. En virtud del paternalismo y de las imágenes autogratificantes establece una relación con la joven Luz María que, como dice el narrador, es una mezcla de amante y falsa hija. Quiere esto decir que el modelo represivo se impone. Ana Isabel quedará como un ideal inalcanzable - por loque colabora en lo represivo-y las prácticas degradadas vienen a subrayar la desviación. Es decir, según se produce una evolución hacia la formación de un imaginario oficial, el sexo adquiere formas más turbias ${ }^{9}$. Dado que el instinto es una fuente de inseguridad, se busca abandonarlo a cambio de la actividad de estadista. Se abre paso la idea de alcanzar una posición de no dependencia que sintoniza con la noción de poder omnimodo.

La degradación de períodos posteriores del presidente se manifiesta en las prácticas seniles y en la tendencia larvada hacia el homosexualismo. Sus apreciaciones sobre la belleza de Fabián y su frustrada paternidad comprueban esta evolución final.

\section{FACTOR IDEOLÓGICO Y CULTURAL.}

Bajo este epígrafe podemos encontrar en la narración una enorme acumulación de semas, por lo que se hace necesario efectuar una selección. Atenderemos, en principio, a aquellos componentes de la figura del protagonista que el autor ha extraido de la historia y de la tradición literaria.

Concibiendo al dictador de acuerdo con una realización efectiva en la historia y en la ficción, el autor lo sitúa en el marco del influjo de la cultura francesa. Por tanto, se le identifica con un modelo europeo que está respondiendo al conocido hecho de la dependencia de los países latinoamericanos en un período preciso y que implica la escisión del personaje. El afrancesamiento es la manifestación de la relación cultural entre ambos continentes en el instante histórico en que da comienzo la narración, en torno a los años veinte. En la reconstrucción del pasado del protagonista se narra irónicamente cómo el joven

'Martha L. Canfield, El "patriarca" de García Márquez. Arquetipo literario del dictador hispanoamericano. Firenze: Universitá degli Studi di Firenze, 1984, 39-45. A propósito de las degradaciones sexuales del dictador. 
ambicioso realiza el viaje a París, para entrar en contacto con aquel mundo por excelencia espiritual. Se recoge aquí el gesto propio de los intelectuales latinoamericanos que solian peregrinar al hogar de la cultura, para volver purificados. Pero también aquí el narrador lima este ideal, lo muestra más como espejismo, pues el joven González Tejada tiene un notable desinterés por lo artístico que ofrece la ciudad. Así, a diferencia del dictador letrado de Alejo Carpentier, la reconstrucción del mundo de la época en su objetualidad, en su menudo ajetreo cultural, no se da. Precisamente porque se ha elegido que el futuro presidente viva sólo pendiente de su estrecha visión personal y se desentienda de la sociedad parisina. En el plan general el autor ha preferido concentrar su objetivo en el tratamiento de los factores ideológicos y de los mecanismos de los aparatos de gobierno y nada lo aparta de ahí.

Su personaje, por todo esto, articula el sema de hombre culturizado a la europea que tiene la misión de civilizar y conquistar para el progreso al país atrasado y bárbaro. Viene a actualizarse una vez más la dicotomía civilización y barbarie, como referencia literaria latinoamericana ${ }^{10}$. En las repetidas consideraciones sobre la morfología de clases y la naturaleza social del país, González Tejada concibe su tarea como armonización de las características extremadas que lo forman y que concluiría en la consecución de un país estable y articulado. Su ideal de gobierno es "el equilibrio francés". Su anhelo es reproducir elélan francés y lo que estoimplica: fundamentalmente su adscripción personal al racionalismo que se comprueba en sus frecuentes menciones al cartesianismo: "El presidente alzó los ojos al cielo y murmuró: "iGracias, Dios mío, por permitirme gobernar a la francesa". Es pues un dictador ilustrado, aunque mucho más humilde y distanciado del modeloque el supremo magistrado de Carpentier. En el caso de Vera, el sarcasmo es también más directo. Lo cierto es que el horizonte histórico viene marcado en su origen y límites por acontecimientos ocurridos en Francia: "La libertad está implantada en el mundo desde la Revolución francesa iy basta!".

En este contexto la reivindicación de un talante racionalista se inscribe, de hecho, en las tradiciones del liberalismo latinoamericano y dentro de su función civilizadora. Para Tejada, inmerso en esa tradición ideológica, racionalismo es un emblema que significa progreso, y que él asume como continuación del conflicto secular entre fuerzas oscurantistas (católicas) y progresistas (liberales), salvo que en este caso lo racional se asume distanciado de cualquier partido, como el impulso que puede neutralizar los conflictos que se alargan desde la fundación del país. Pero como ya desde las primeras líneas de la novela -desde el perfil biográfico - se indica, el dictador es un manipulador que practica el oportunismo vehementemente. El racionalismo, en realidad, corresponde al aspecto imaginario del dictador y al oficial, es decir, de imagen, ya que carece

${ }^{10} \mathrm{John}$ S. Brushwood, La novela hispanoamericana del siglo XX. México, FCE, 1984. Este mismo tema de la continuación en la dictadura del esquema "Civilización" y "Barbarie" es tratado por Brushwood, entre otros criticos. 
de un pensamiento coherente. Su formación intelectual es frágil. Por su carácter, por la confusión de susideas, acepta todolo que juzgue beneficioso para su empresa. En realidad, como macro-definición del personaje, de ser lo contrario de lo que pretende, es lo opuesto a la exigencia y rigor del racionalismo cartesiano ${ }^{11}$. Es otro recurso del método pero más caótico y grotesco. Como vimos, está dispuesto a servirse de prácticas mágicas y, por el poder ancestral de la Iglesia, acepta los símbolos y actos supersticiosos católicos, lo que explica su "Como Descartes soy un sacerdote de la razón y un fiel de la eucaristía". El racionalismo, en estas condiciones, queda como algo residual que se identifica con el desarrollismo o sus propias imaginaciones deseantes. Uno de los ejemplos de esta inversión de la pretensión racionalista es la recurrencia a las actos de hechicería y su intento de aplicarlos a cuestiones políticas de especial dificultad, como también su vuelta al uso de bebedizos en los compases finales de la narración. Basta con recordar algún pasaje como "Cierto que en sus lucubraciones, sus sistemas se entremezclaban con la tradición arraigada y con sus temores irracionales, hasta producir un laberinto racionalista-metafísico". O bien releer uno de los episodios de la hechicera:

(...) extrajo el escapulario bendito que le obsequió el Arzobispo y que había mantenido relegado, pues un racionalista, por muy catolico que fuera, no podía creer en fetiches. Pero (...) ¿por qué no defenderse con un amuleto de la santa religión de sus mayores, más aún si era también la religión de su pueblo? (36)

Otro de los componentes más significativos es el de su teatralidad. Esta cuenta con la capacidad oratoria y el gestualismo. En oposición a los dictadores silenciosos, doctorales, correctos, atemorizantes, raramente visibles, el de Vera es el actor que lleva la política representativa a su epítome, a la teatralidad. Como afirma Badiou, en buena ley, no hay discurso de la dictadura (fascista) sino variantes que responden al tipo de derrota popular. En esta ocasión, a merced de la situación, su fuerza visible descansa en la debilidad de las masas. En la gestualidad de los dedos, en la verbosidad demagógica, que no puede contener, a pesar de que se diga: "El se hablaba a sí mismo, para filtrar sus palabras", se halla una prueba más de la inevitable realidad de falsear u ocultar. $Y$ encuentra algo firme en el dominio de la palabra: "Siguió hablando impetuosamente (...) Voz profunda que increpaba, y amenazaba (...) que acariciaba a la tierra ausente (...) Todo sincronizado con ademanes tormentosos y miradas fulminantes." o "Dadme un balcón en cada pueblo, no necesito más".

Las salidas a la terraza del palacio muestran la calidad teatral del dictador para imaginarse a sí mismo. Es parodia, ciertamente, pero también el hecho

\footnotetext{
11 Sobre la cuestión de lo cartesiano, en este caso a propósito del dictador de Carpentier, véase Mejía Duque, "Los 'recursos' de Alejo Carpentier", Casa de las Américas, 89, 1975, $155-58$.
} 
habla de su propia imagen. La escenografía es natural y social. Sale al balcón bajo la grandiosidad de la noche - según un tradicional modelo romántico-y con la protección de "los cerros guardianes" (el "volcán tutelar" de Carpentier), en la conciencia de que un héroe histórico debe cumplir ciertos gestos y actos. La figura alerta en la que "sólo las estrellas vigilaban con él" se ha hecho motivo del género. Aquí, no obstante, la referencia a los trasnochadores rebaja el posible significado atemorizante. Ensaya poses como la de fruncir el ceño, cruzar los brazos. La referencia a lo pétreo, como estatua viviente, alude al modelo mussoliniano. Es todo el episodio una parodia de la gestualización dictatorial. Inmóvil, tieso, teniendo a la catedral como referencia, configura la imagen de un ser eterno, dotado de grandeza. En esa plaza tendrá lugar el acto final del reconocimiento y apoteosis de Gabriel como el arquetipo ancestral que vive inmerso en la psique de los individuos. Es la perduración de la barbarie tradicional en el XIX y en nuestro siglo.

Lo teatral está también en otras secuencias como la de la exhibición deportiva, subiendo pisos y convenciendo por esa hazaña. Pero desde esta base podemos conectar con otro punto importante en la construcción del personaje y la novela. Este concepto se amplía y propaga en una serie que engloba pantomima, monigote, muñeco, pelele, y que plantea la cuestión de quién domina o decide y que, por tanto, afecta a la naturaleza misma del poder dictatorial. Se viene a postular que es una entidad que se realiza en la representación como falsedad y en el dictador como un muñeco manejado por otros, en este caso, las mujeres, los validos y camarillas -que también pueden ser manipulados-, o finalmente por empresarios (Mr. Castilla) representantes del capital y del imperio de EE.UU. El autor postula que el último símbolo de la dictadura es el monigotismo. La conciencia mixtificada del dictador está atravesada por una constante preocupación sobre la cuestión de mando, originada en aquella experiencia primera con los militares, “(...) y lo que quieren es adueñarse de González Tejada hacerlo su muñeco. Y como no pueden enamoran a los militares", "Pero mientras tanto, todos querian manejarlo. ¡No soy un bien mostrenco!"; "Pero me dio la orden y antes principios sabios. Estará orgulloso de mí y como sabe que no soy un pelele deja lo demás a mi iniciativa"; "(...) no entienden que el hombre grande no es un muñeco de una sola pieza sino una bandera (...); ; Mejor que la haya olvidado así nadie puede dominarme no necesito de nadie"; "reducido a ser el protagonista de una comedia de las burlas"; “(...) y mejor así porque no dependo tanto de los militares. ¡No dependo de nadie! 'Sólo dependes de mî dice Marjorie pero qué importa (...)". En esta serie de monólogos y divagaciones del dictador se comprueba cómo percibe y reprime en este escenario intimo el hecho de ser un monigote.

Como consecuencia de esta circunstancia y de las relaciones de desconfianza, manipulación, ambición, etc., se genera una situación de inseguridad que obliga a no depender, a aislarse y, así, verse abocado a la soledad. El tópico de la 
soledad del dictador ${ }^{12}$ aparece en esta novela primero como una de las muchas imposturas del presidente, que viene a ser una parodia y un tratamiento nuevo del motivo, pero hay esta segunda, que él no puede manipular pero que es la que padece y que se da como efecto real de las estructuras de poder. En su mixtificación sufre y al mismo tiempo manipula la soledad como creyendo que la domina, sin hacerlo.

En la novela, haciéndose eco de acontecimientos históricos, hay un protagonismo popular revolucionario que, no obstante, dado el marco térico de sustancialidad social, literariamente supone la repetición de las limitaciones del realismo social del pasado. Lo ejemplar de las conductas de los revolucionarios, el tono beato de la expresión hacen que fracasen como soluciones estéticas. Junto a éstos aparecen los indios. Su papel es sólo ocasional, puntual, con la intención de crear un contrapunto crítico e irónico al dictador. Lo que puede ser grave es la reproducción de soluciones, marca Jorge Icaza. Lo atestiguan los diálogos en letanía, lo anónimo de estos personajes, el mismo estilo en ciertos pasajes y la sospecha de que la interpretación de la cuestión indígena no ha variado mucho en los últimos 40 años para Pedro J. Vera, desde los planteamientos icacianos. Ahora la noción que los unifica es la ilusión, implantada como argumento irrebatible y nunca escindido.

La novela expone, a través del tratamiento del pueblo, la revolución, la sociedad y el Estado, una intensa crítica que, sin embargo, resulta incapaz de sustraerse a la constatación de la repetición del fenómeno dictatorial.

12 Puede compararse con lo que dice Dasso Saldívar, "Acerca de la función política de la soledad en El otoño del patriarca", La Estafeta Literaria, 561, 1975, 4-5. 